\title{
Fatigue strain mapping via digital image correlation for Ni-based superalloys: The role of thermal activation on cube slip
}

\author{
Alberto W. Mello, Andrea Nicolas, Michael D. Sangid* \\ School of Aeronautics and Astronautics, Purdue University, 701 W. Stadium Ave, West Lafayette, IN 47907-2045, USA
}

\section{A R T I C L E I N F O}

\section{Keywords:}

Ni-based superalloys

Cube slip

Microstructure

Digital image correlation

Fatigue

\begin{abstract}
A B S T R A C T
A deformation mechanism map for a Ni-based superalloy is presented during cyclic loading at low $\left(300{ }^{\circ} \mathrm{C}\right)$, intermediate $\left(550{ }^{\circ} \mathrm{C}\right)$, and high $\left(700^{\circ} \mathrm{C}\right)$ temperatures for low $(0.7 \%)$ and high $(1.0 \%)$ applied strain amplitudes. Strain mapping is performed via digital image correlation (DIC) during interrupted fatigue experiments at elevated temperatures at 1, 10, 100 and 1000 cycles, for each specified loading and temperature condition. The DIC measurements are performed in a scanning electron microscope, which allows high-resolution measurements of heterogeneous slip events and a vacuum environment to ensure stability of the speckle pattern for DIC at high temperatures. The cumulative fatigue experiments show that the slip bands are present in the first cycle and intensify with number of cycles; resulting in highly localized strain accumulation. The strain mapping results are combined with microstructure characterization via electron backscatter diffraction. The combination of crystal orientations and high-resolution strain measurements was used to determine the active slip planes. At low temperatures, slip bands follow the $\{111\}$ octahedral planes. However, as temperature increases, both the $\{111\}$ octahedral and $\{100\}$ cubic slip planes accommodate strain. The activation of cubic slip via cross-slip within the ordered intermetallic $\gamma$ ' phase has been well documented in Ni-based superalloys and is generally accepted as the mechanism responsible for the anomalous yield phenomenon. The results in this paper represent an important quantifiable study of cubic slip system activity at the mesoscale in polycrystalline $\gamma-\gamma$ ' Ni-based superalloys, which is a key advancement to calibrate the thermal activation components of polycrystalline deformation models.
\end{abstract}

\section{Introduction}

Strain localization is a precursor to fatigue crack initiation. As opposed to elastic deformation, the primary mechanism for plasticity in polycrystalline materials is mediated by localized, inhomogeneous slip events. As discussed by Seeger, the flow stress in crystalline materials can be decomposed into athermal and thermal components [1]. At absolute zero temperature, the maximum resistance to dislocation glide is known as the mechanical threshold, while at finite temperatures, slip proceeds below the mechanical threshold with the assistance of thermal activation $[2,3]$. Thermally activated dislocation motion is governed by an Arrhenius expression for the shear strain rate on a slip system as a function of the activation energy [2]. The kinetics of plasticity theory is based on a statistical description to express the thermal dependence for an ensemble of dislocations [3]. Thus, it is necessary to capture a statistically representative set of individual slip events to faithfully capture the kinetics of polycrystalline deformation, which has been a longstanding issue for the materials community. In this paper, we present an experimental approach to capture the deformation in polycrystalline Ni-based superalloys as a function of temperature, during cyclic loading.

Ni-based superalloys exhibit anomolous yield behavior, such that the material does not exhibit a significant decrease in the yield strength between room temperature and $\sim 700{ }^{\circ} \mathrm{C}$. This phenomenon is atypical of engineering alloys, and in fact the strength often increases over this range of temperatures, which is a beneficial attribute of superalloys $[4,5]$. Through detailed experiments of single crystalline material, the anomolous yield behavior has been attributed to the role of the $\gamma^{\prime}$ precipitates (ordered phase with a $\mathrm{L}_{2}$ structure) and is more pronounced with increase volume fraction of $\gamma$ ' [6,7]. The anomolous yield characteristics of superalloys have garnered significant attention over the last four decades and the most common explanation is a cross-slip mechanism of the dislocations from the octehedral $\{111\}$ planes to the cubic $\{100\}$ planes. The cross-slipped dislocation segments are immobile and result in a strengthening mechanism via the formation of the widely accepted Kear-Wilsdorf locking mechanism [8].

The activation of $\{100\}$ cubic slip systems at elevated temperatures in Ni-based superalloys has been characterized within single crystals

\footnotetext{
* Corresponding author.

E-mail address: msangid@purdue.edu (M.D. Sangid).
} 
and associated theories have explained this phenomenon. Through detailed experiments performed on single crystals via slip-line trace analysis, Staton-Bevan and Rawlings observed the thermally-activated transition to cubic slip planes [9]. Atomic simulations by Paidar et al. have provided the basis for the orientation dependence and tension/ compression asymmetry of the anomolous yield behavior based on anisotropy of the antiphase boundary energy (APBE) [10]. As discussed in a review paper by Reed and Rae [11], the APBE on the $\{100\}$ plane is less than that on the $\{111\}$ plane, as observed by Dimiduk et al. which quantified these values over a range of binary $\mathrm{Ni}_{3} \mathrm{Al}$ single crystals via transmission electron microscopy [12]. Many of these classical studies have been on monolithic structures, but similar cube slip phenomena has been observed in $\gamma-\gamma^{\prime}$ single crystalline materials [13-18].

For single crystals of $\gamma^{\prime}$ strengthened Ni-based superalloys with loading along the [111] direction, Bettge and Österle alternating slip on $\{111\}$ planes following a zig-zag manner in the matrix channels, such that the overall slip (across a longer length scale) was along a cubic $\{100\}$ slip system [18]. Additionally, the observed dislocation glide on either the $\{111\}$ or $\{100\}$ planes in the $\gamma$ ' particles [18]. Due to the observations of cubic slip systems, many crystal plasticity models for high temperature deformation permit slip on the octehedral and cubic slip systems in their flow rules, please refer to the models for single crystal [19-22] and polycrystalline Ni-based superalloys [23,24] to name a few. For these models of polycrystalline deformation, it is difficult to account for the kinetics of slip along the different families of slip systems, and detailed experiments are missing at the relevant length scales to quantify the deformation accomodated by the octehedral and cubic slip systems as a function of temperature. Daymond et al. used neutron diffraction to characterize strain in Ni-based superalloys as a function of temperature [25]. Through a self-consistent polycrystalline modeling approach, they concluded that the cubic $\{100\}$ slip systems are active in the $\gamma$ ' precipitates at elevated temperatures. While this approach represents ensemble activation of the cubic slip system, there has yet to be a full field determination at the grain level scale of $\{100\}$ slip. One such method to map the heterogeneous deformation relative to the microstructure is digital image correlation coupled with electron backscatter diffraction.

Digital image correlation (DIC) involves tracking features on the material surface, in order to obtain a spatial field of the displacement and associated strain. As demonstrated by several researchers [26-33], since this method is scale invariant, DIC can be performed within a scanning electron microscope (SEM) to provide high resolution strain mapping. Further to understand the role of temperature, DIC has been used at elevated temperatures using optical methods [34], ultraviolet optics [35], and electron microscopy [28,36,37]. The present paper uses high resolution DIC to understand the kinetics of plastic deformation during cyclic loading of a polycrystalline Ni-based superalloy. Specifically, a deformation map of the slip systems activity and accommodation of strain during cyclic loading are examined as a means to understand strain localization and the associated fatigue crack initiation, as a function of temperature.

\section{Materials and experimental procedures}

\subsection{Sample preparation}

The material analyzed in the present work is a powder processed Nibased superalloy, RR1000, supplied by Rolls-Royce plc. The material is a supersolvus heat-treated, coarse grain variant of RR1000 and hence it contains no primary $\gamma$ '. Details of the heat treatment can be found in ref [38]. The cooling rate of the material from the solution temperature was controlled, in order to optimize the secondary $\gamma^{\prime}$ size. The mean maximum feret diameter of the secondary $\gamma^{\prime}$ was measured as $\sim 300 \mathrm{~nm}$ via high resolution SEM imaging after a Kalling's etch. The coarse grain RR1000 has a target average grain size of $30 \mu \mathrm{m}$ [38]. The material was machined by electro-discharge machining to obtain the final sample

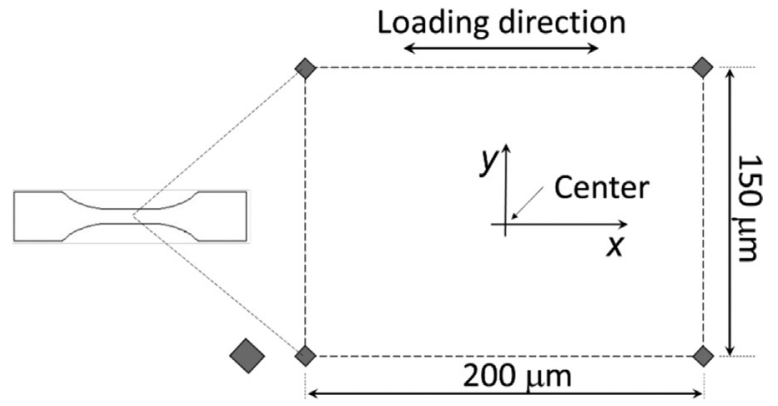

Fig. 1. Delimited area for EBSD and DIC analysis and pertinent coordinate system.

geometry. The samples have a dog bone shape, with $10 \mathrm{~mm}$ gauge length, cross sectional area $3 \mathrm{~mm}$ wide and $1.25 \mathrm{~mm}$ thick. All samples were polished on 1200 grit sand paper for about five minutes on both sides and then left in a vibro-polisher with colloidal silica $0.05 \mu \mathrm{m}$ for $24 \mathrm{~h}$ for a mirror like surface on one of the sides. An area of interest (AOI) is delimited in the center of the best polished side of each specimen. Fiducial marks are placed using a LECO Microhardness Tester LM247AT. The areas are identified in the specimen as shown in Fig. 1.

For grain identification and proper lattice orientation of each grain, we mapped each AOI with electron backscatter diffraction (EBSD) scans in a FEI Philips XL-40 SEM, with the following acquisition settings: $25 \mathrm{kV}$ accelerating voltage, spot size $5,100 \mu \mathrm{m}$ aperture, $18 \mathrm{~mm}$ working distance, 70-degree tilt. For the EBSD setup in the EDAX system, we used gain of 12.85, black level 5.4, 60-millisecond exposure time, and a step size of $0.90 \mu \mathrm{m}$. A typical result for the EBSD scan is shown in Fig. 2(a), by means of the AOI inverse pole figure (IPF) representation with the associated color map (Fig. 2(c)).

After mapping the AOI texture, the specimen was speckled with $\mathrm{Ti}$ nano-powder for digital image correlation (DIC). The procedure for applying Ti speckles was the same described by Tracy et al. [37]. A colloidal solution was created with Ti nano-powder $(60 \mathrm{~nm})$, Bicine and distilled water. The Bicine plays an important role in this solution for changing the $\mathrm{pH}$, facilitating the fragmentation of $\mathrm{Ti}$ nano-powder agglomerates. The solution was roll milled for $24 \mathrm{~h}$ prior use. To help the agglomerate breaking process, small G5 SiC bearing balls were placed inside the vial with the solution during the 24-h roll mill. After $2 \mathrm{~h}$ of resting, the solution was applied on the specimen surface by drop casting. Upon drying, the specimen was heated to $300{ }^{\circ} \mathrm{C}$ for $10 \mathrm{~min}$ to burn off all the Bicine. The Ti speckling has shown to provide good adherence to the substrate, resistance to high temperature, and no interaction with the $\mathrm{Ni}$ matrix for temperatures below $900{ }^{\circ} \mathrm{C}$, allowing the proposed fatigue tests, keeping the monitored pattern intact. Fig. 2(b) shows an example of Ti speckled pattern on a specimen image at 3,500x. To cover the entire AOI, 9 images were taken in sequence $(3 \times 3)$ to form the field of view (FOV) and subsequently stitched together.

\subsection{Equipment and loading parameters}

All experiments were performed inside a vacuum chamber using a modified MTI load frame with a heater fixed in the bottom of the frame. The heater was connected to a control box that could maintain the targeted temperature within $\pm 15{ }^{\circ} \mathrm{C}$. The control thermocouple was connected to the center of the heater element. Four extra thermocouples were used to monitor the following points: (a) top of the specimen gauge section, (b) load cell, (c) displacement sensor, and (d) actuator motor. Fig. 3 displays the frame and its components inside the vacuum chamber.

The sample was heated to the desired temperature while the load was kept at a slightly positive value. It is important to notice that during the heating period the load control must be active to avoid compressive 

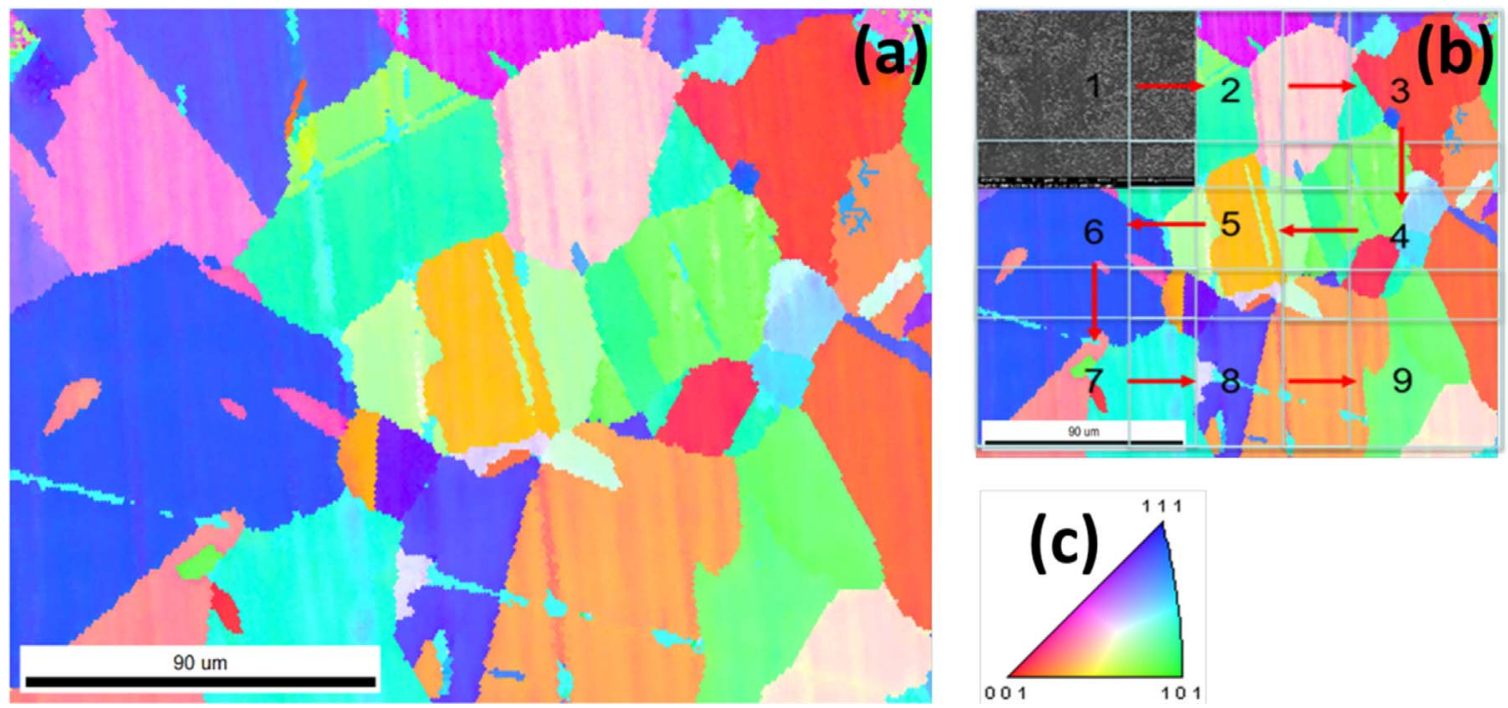

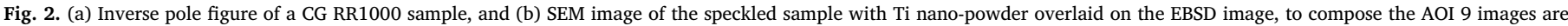
acquired and stitched together. (c) IPF color code.

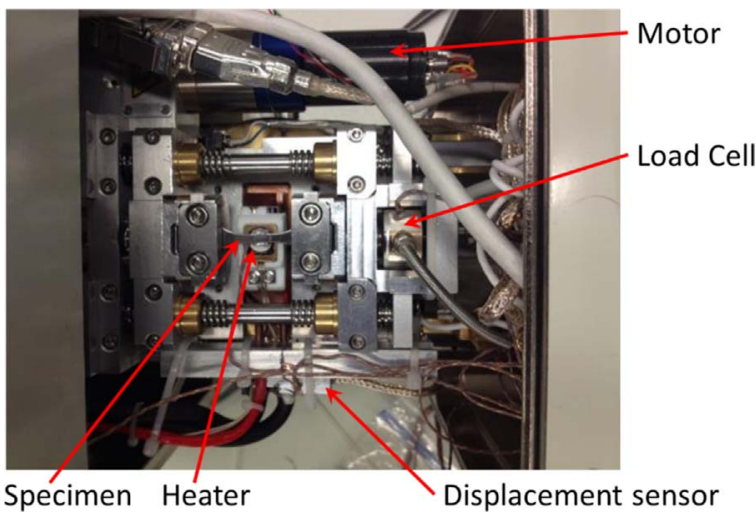

Fig. 3. Load frame assembled inside the vacuum chamber.

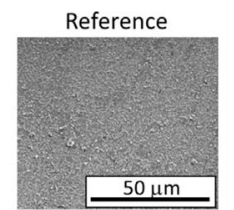

Fatigued

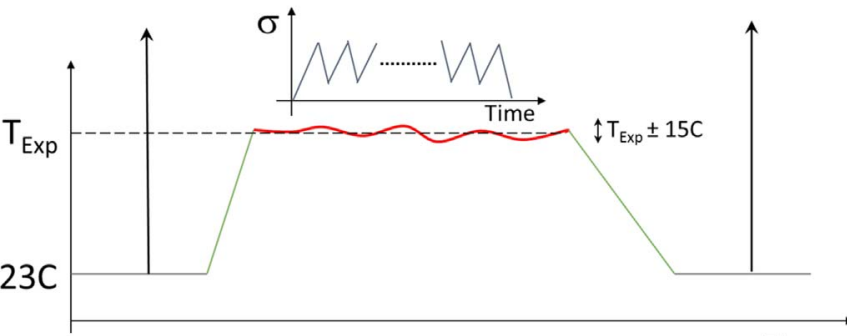

Time

Fig. 4. Overview of the high temperature fatigue experiment.

Table 1

Low cycle fatigue test parameters - temperatures and initial strains. The values in the table represent the interrupted fatigue cycles at which strain maps were acquired.

\begin{tabular}{llll}
\hline $\begin{array}{l}\text { Temperature } \\
\text { Initial Strain }(\Delta \varepsilon)\end{array}$ & $\begin{array}{l}\mathbf{3 0 0}{ }^{\circ} \mathbf{C} \\
\text { (Cycles) }\end{array}$ & $\begin{array}{l}\mathbf{5 5 0}{ }^{\circ} \mathbf{C} \\
\text { (Cycles) }\end{array}$ & $\begin{array}{l}\mathbf{7 0 0}{ }^{\circ} \mathbf{C} \\
\text { (Cycles) }\end{array}$ \\
\hline $0.7 \%$ & $(1,10,100,1000)$ & $(1,10,100,1000)$ & $(1,10,100)$ \\
$1.0 \%$ & $(1,10,100,1000)$ & $(1,10,100,1000)$ & $(1,10,100)$ \\
\hline
\end{tabular}

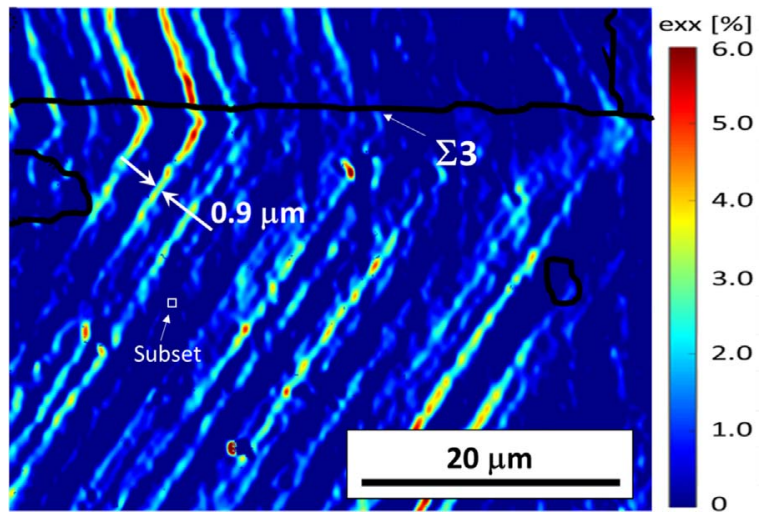

Fig. 5. Magnified region of a DIC strain map after bias correction, with well-defined detail of individual slip bands (on the order of $0.9 \mu \mathrm{m}$ in width) interacting with a twin boundary. The representative subset size, $0.65 \mu \mathrm{m}$, is depicted.

load in the specimen due to thermal expansion. The same has to be done during the cooling process to avoid excessive tension. After the desired temperature is reached and stabilized, the cycles were applied at $0.15 \mathrm{~Hz}$. Fig. 4 depicts the sequence adopted for the experiments. All experiments were performed at a pressure of $7 \times 10^{-4} \mathrm{~Pa}$ $\left(5 \times 10^{-6}\right.$ Torr $)$.

Each sample was loaded to an assigned initial total strain $(0.7 \%$ or $1.0 \%$ and then unloaded for DIC verification of the first cycle. The subsequent cyclic loading was then applied under stress control according to the stress value achieved after the initial loading cycle with a stress ratio, $\mathrm{R}=0.1$. The modified cyclic loading profile cannot accommodate cyclic hardening and is susceptible to ratcheting. The average applied strain rate for this experiment is $3 \times 10^{-3} 1 / \mathrm{s}$. Six samples were tested under fatigue loading at different temperatures. Table 1 shows the summary of the tests performed based on the initial strain and temperature for each experiment. For the $300{ }^{\circ} \mathrm{C}$ and $550{ }^{\circ} \mathrm{C}$ experiments, all the specimens were cycled up to 1000 cycles and analyzed at $1,10,100$ and 1000 cycles. For $700{ }^{\circ} \mathrm{C}$, the $0.7 \%$ specimen failed prior to reaching 1000 cycles. For the $1.0 \%$ specimen, the experiment was interrupted at 100 cycles for the final DIC analysis.

\subsection{DIC bias correction}

Scanning electron microscopy can provide high magnification images that potentially allows for high resolution DIC analysis necessary to capture individual slip bands. However, researches have shown 

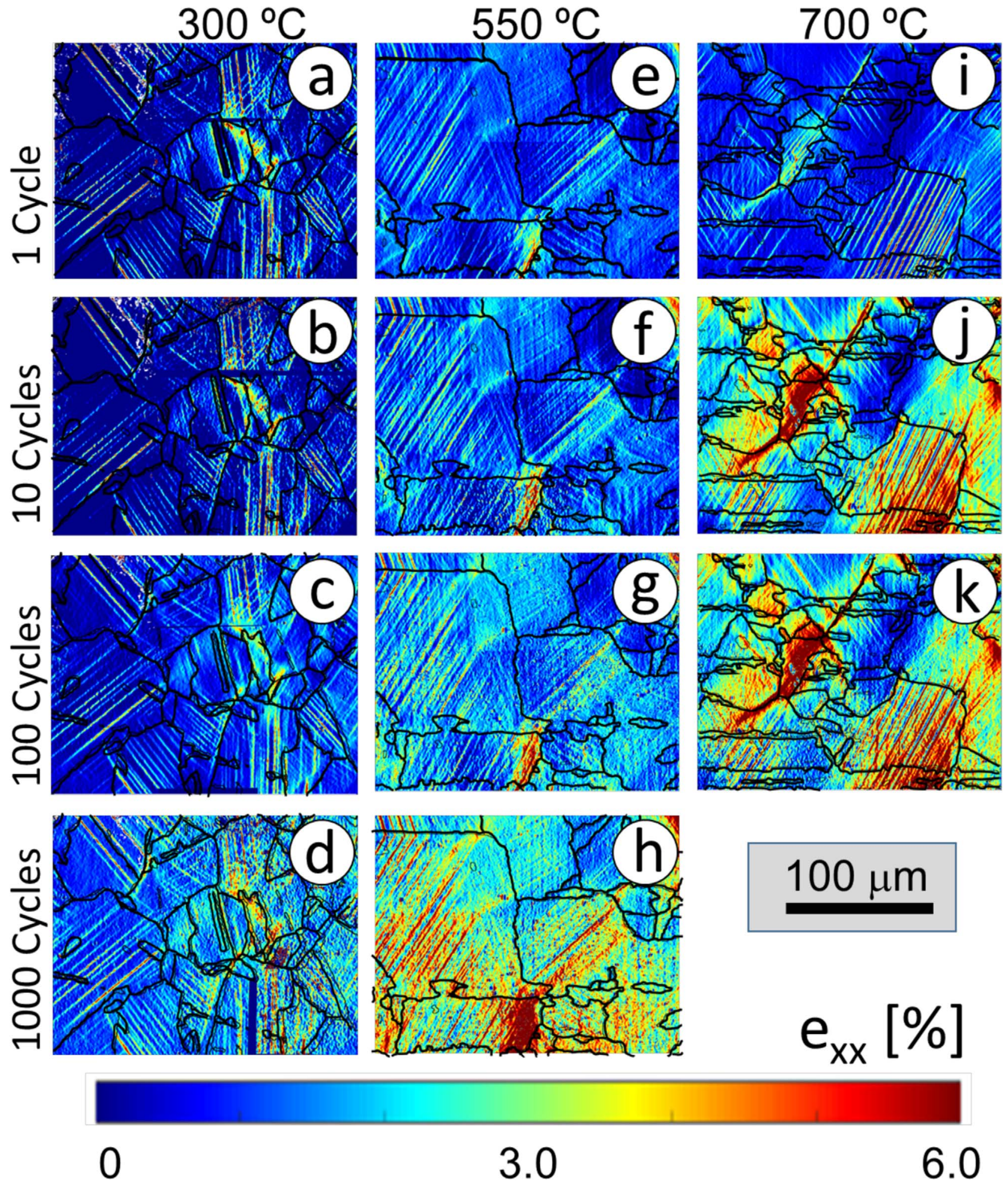

Fig. 6. Strain evolution for CG RR1000 specimens at $300{ }^{\circ} \mathrm{C}, 550{ }^{\circ} \mathrm{C}$ and $700{ }^{\circ} \mathrm{C}$ mapped at $1,10,100$ and 1000 cycles, loaded to $0.7 \%$ initial strain.

that digital image correlation performed from SEM images can lead to problems not seen in optical images [39-42], specifically biases and aliasing from the electromagnetic distortion. It has been reported that occurrences of drift, spatial distortions and magnification uncertainties can affect the resolution and accuracy of the mapped strains. All the DIC strain maps were corrected according to the protocol presented by Mello et al. [43]. The objective of performing the corrections is to minimize any erroneous result coming from spatial distortions and uncertainty in the magnification. The spatial distortion was corrected based on the image of a certified grid taken side by side with the specimen, for every image acquisition. The same grid was used to verify and correct for discrepancies in the reported magnification values by the SEM, which occur in ex-situ experiments during the acquisition measured days or weeks apart [43]. Finally, optimizing the SEM acquisition parameters and properly grounding the samples reduced the drift effect.

The spatial distortion and magnification corrections increased the resolution of the DIC measurement by further reducing the subset size 

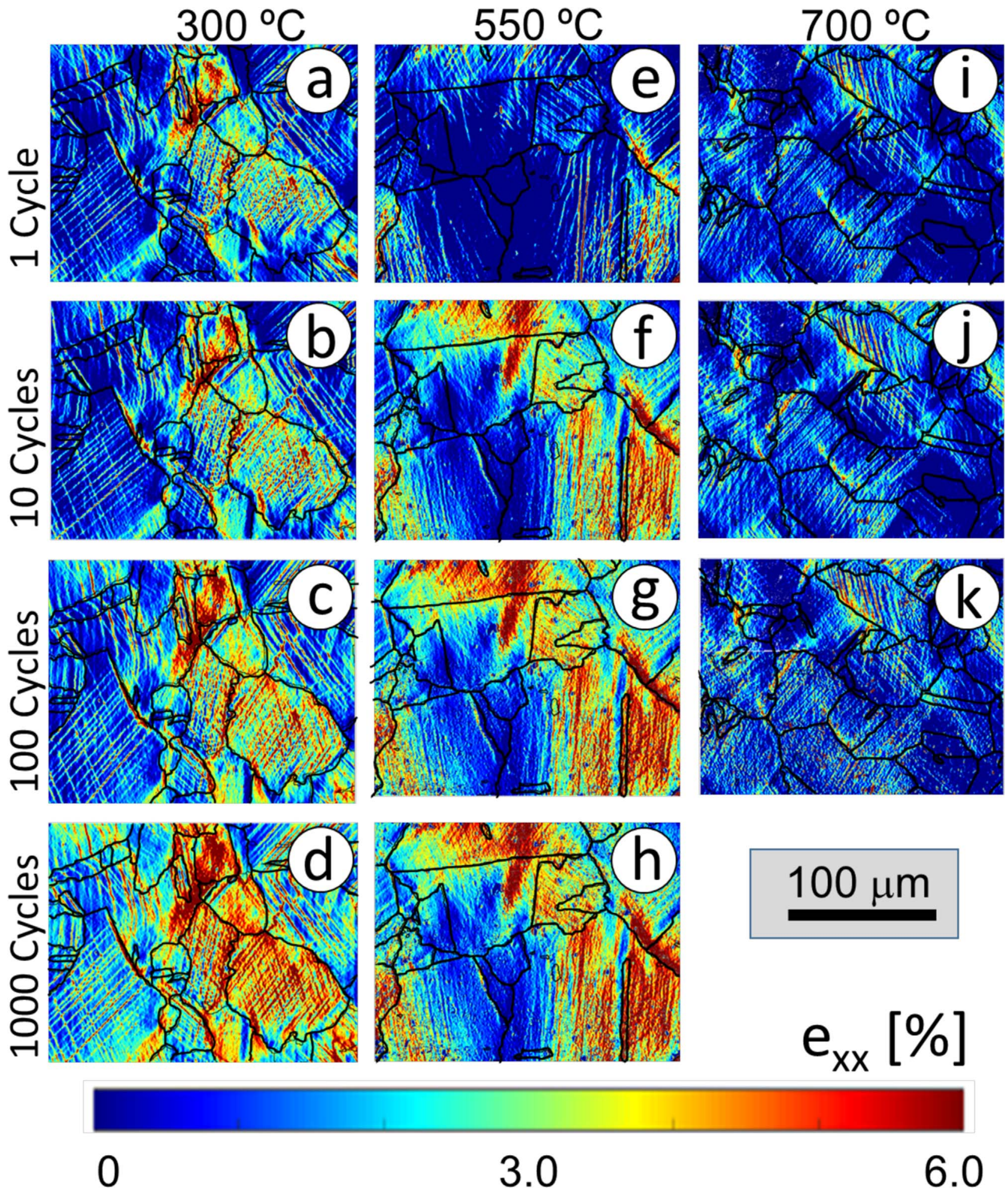

Fig. 7. Strain evolution for CG RR1000 specimens at $300{ }^{\circ} \mathrm{C}, 550{ }^{\circ} \mathrm{C}$ and $700{ }^{\circ} \mathrm{C}$ mapped at $1,10,100$ and 1000 cycles, loaded to $1.0 \%$ initial strain

for the analysis, thereby improving the precision of the localized measurements. After the proposed correction, we could resolve the strain field using a subset size of $0.65 \mu \mathrm{m}$, with $0.05 \mu \mathrm{m}$ step size, keeping the strain uncertainty below $0.1 \%$ for all the cases presented in this work. This was sufficient to track and quantify the strain in individual slip bands, as shown in Fig. 5.
3. Results and discussion

\subsection{Strain evolution}

As described in Section 2.2, 6 specimens were tested under fatigue loadings for different applied strain levels and temperatures. The strain evolutions for $0.7 \%$ and 1.0\% initial strain are shown in Figs. 6 and 7, respectively. For all images, the contour plots of the local strain had a 


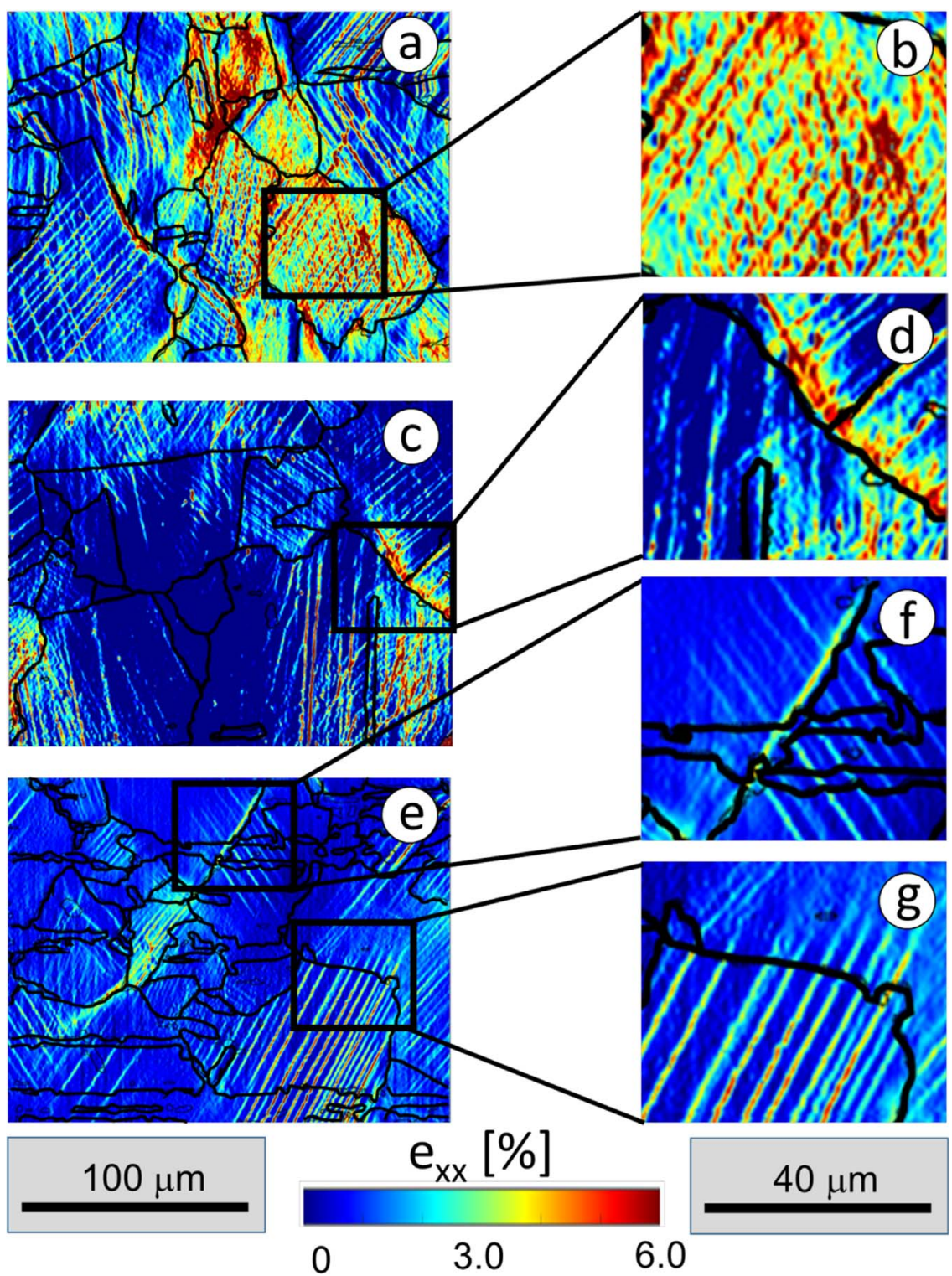

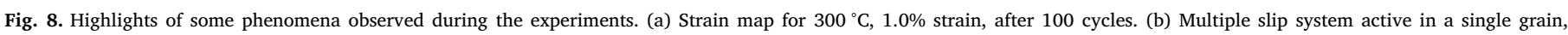

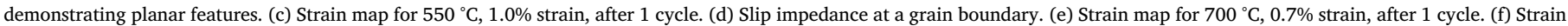
accommodated at the grain boundary and possible signs of grain boundary sliding. (g) Slip transmission across a grain boundary.

maximum strain value depicted as $6 \%$, but higher strain levels were measured in distinct regions. Similarly, the minimum strain plotted is $0 \%$, although local regions of compression were characterized. The lines representing values of high strain capture slip bands following an active slip plane. As can be visualized in Figs. 6 and 7, the slip bands are present in the first cycles and intensify with respect to the value of strain with number of cycles. It should be noted that the slip bands do not increase in thickness during cyclic loading. Additional slip lines are not observed during the fatigue progression, thus additional slip activity was not initiated within the grains, the distance between slip bands within a given grain remains relatively consistent with respect to loading cycles. These phenomena can be explained as follows. The initial loading cycle (either to $0.7 \%$ or $1.0 \%$ initial strain) is past the macroscopic elastic to plastic transition of the material. Thus, during the onset of plasticity, dislocations cut through the tertiary $\gamma^{\prime}$ precipitates in the material, thus effectively weakening the precipitate as an obstacle for subsequent dislocation motion. The weakened path is a consequence of the sheared $\gamma^{\prime}$ particle exhibiting a reduced effective size and ordering of the $\mathrm{L}_{2}$ intermetallic structure. Therefore, during the subsequent loading steps, the microplasticity events include addi- tional dislocations traveling along the same paths, which exhibit a reduced energy barrier for slip. The results lead to dislocation confinement to well define glide planes and planar slip features.

For initial strains of $0.7 \%$ at $300{ }^{\circ} \mathrm{C}$, the activity on the slip planes was still increasing at 1000 cycles. At $550{ }^{\circ} \mathrm{C}$, the strain saturation seems to occur between 100 and 1000 cycles, while at $700{ }^{\circ} \mathrm{C}$, saturation occurs between 1 and 10 cycles. For $1 \%$ initial strain, it was observed at $300^{\circ} \mathrm{C}$, high strain localization was already present in the first cycle, yet the strain activity increased through 1000 cycles. At $550{ }^{\circ} \mathrm{C}$, the saturation happens between 1 and 10 cycles, much faster than for $0.7 \%$ applied strain at the same temperature. The main difference in the strain evolution was observed for $1 \%$ initial strain at $700{ }^{\circ} \mathrm{C}$, where the strain maps appear qualitatively similar from 1 to 100 cycles, with slight increase in the quantitative average macroscopic strain experienced in the AOI. It should be noted that the area of interest is rather small 150 by $200 \mu \mathrm{m}$, compared to the dimensions of the specimen. Thus, the DIC measured strain is not necessarily indicative of the macroscopic strain of the sample in each case.

More importantly, the strain maps elucidate the kinetics of plastic deformation at the grain scale. From the slip events, including both the 

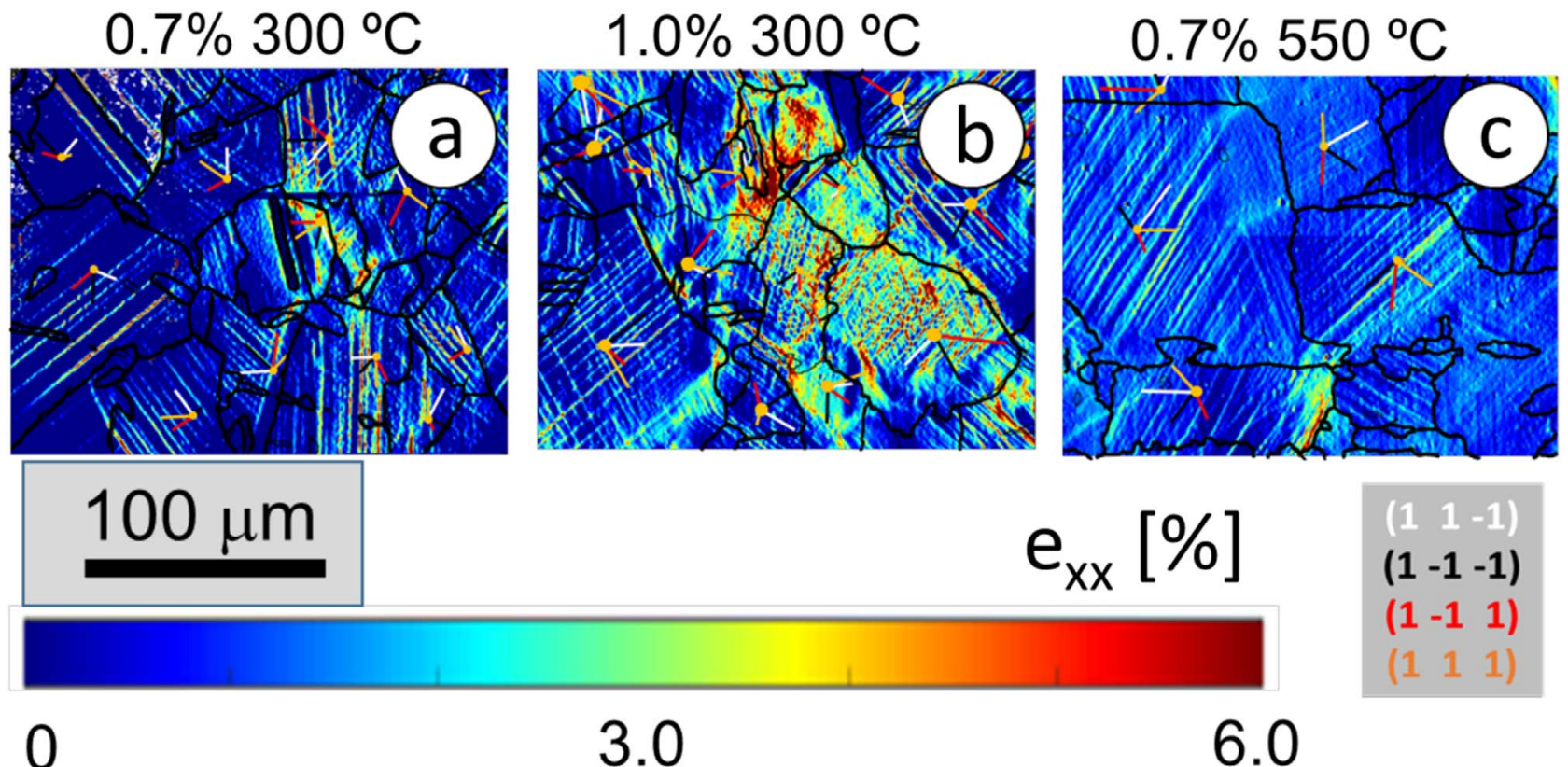

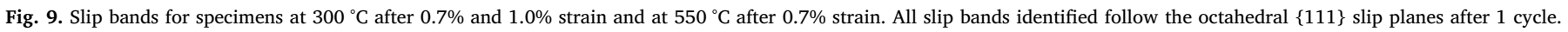

magnitude of slip accommodated by each band and the distance between slip bands, we can infer the thermally activated components of slip for an ensemble of dislocations [2,3]. This information is critical to validate polycrystalline deformation models, where it is difficult to capture the kinetics of the incipient slip events. Moreover, during cyclic evolution, the strain accommodated within the bands saturate as a function of temperature, applied strain, and number of cycles provides important information for the self-hardening of dislocation glide occurring within the slip bands.

The high-resolution strain maps allow us to observe individual slip field characteristics and interactions, as shown in Fig. 8. Fig. 8a,b displays two slip systems activated within a large grain, both displaying planar slip features. In Fig. 8d, slip is obstructed by the grain boundary, leading to dislocation pile-up at the grain boundary and strain localization. Alternatively, in Fig. 8g, the slip is transmitted through the grain boundary. Therefore, the DIC images provide sufficient resolution to study slip-GB interactions at the mesoscale. As shown in Fig. 8e,f, at $700{ }^{\circ} \mathrm{C}$ and $0.7 \%$ applied strain, a significant portion of strain is accommodated by the grain boundary, which could depict grain boundary sliding, albeit more analysis is needed to identify this potential mechanism.

\subsection{Slip system activity}

The high-resolution DIC images allow for analysis of the slip activity during loading at the mesoscale. From the EBSD scan, the orientation of each grain (Euler angles) in the scan was obtained. From the Euler angles, $\left(\varphi_{1}, \Phi, \varphi_{2}\right)$, the rotation matrix, $\boldsymbol{g}$, of each grain is determined according the Bunge definition.

$g=\left[\begin{array}{ccc}\cos \varphi_{1} \cos \varphi_{2}-\sin \varphi_{1} \sin \varphi_{2} \cos \Phi & \sin \varphi_{1} \cos \varphi_{2}+\cos \varphi_{1} \sin \varphi_{2} \cos \Phi & \sin \varphi_{2} \sin \Phi \\ -\cos \varphi_{1} \sin \varphi_{2}-\sin \varphi_{1} \cos \varphi_{2} \cos \Phi & -\sin \varphi_{1} \sin \varphi_{2}+\cos \varphi_{1} \cos \varphi_{2} \cos \Phi & \cos \varphi_{2} \sin \Phi \\ \sin \varphi_{1} \sin \Phi & -\cos \varphi_{1} \sin \Phi & \cos \Phi\end{array}\right]$

Afterwards, a family of planes, $\boldsymbol{n}_{\boldsymbol{i}}$, can be transformed from the crystal frame to the sample frame.

$n_{i}^{\text {sample }}=g^{T *} n_{i}^{\text {crystal }}$

In this notation, $\boldsymbol{n}_{\boldsymbol{i}}$, is a vector representing the family of planes, such that $i: 1-4$ to represent the $\{111\}$ octahedral planes in the FCC configuration, specifically $(111),(\overline{1} 11),(1 \overline{1} 1),(11 \overline{1})$. As shown in Fig. 9, the strain maps after 1 cycle are displayed and the family of octahedral slip planes are superimposed on each grain for the cases of (a) $300{ }^{\circ} \mathrm{C}, 0.7 \%$, (b) $300{ }^{\circ} \mathrm{C}, 1.0 \%$, and (c) $550{ }^{\circ} \mathrm{C}, 0.7 \%$. It is observed that all slip bands follow the well-defined $\{111\}$ slip planes. It is noted that throughout this section, slip plane activation refers to the mesoscale activity and does not consider individual dislocation mechanics that may cross-slip, glide, or dissociate at lower length scales.

As shown in Fig. 10, a distinct shift in slip system activity is observed at elevated temperatures. For Eq. (2), the cubic slip planes are represented as a vector for the family of $\{100\}$ planes, $\boldsymbol{n}_{\boldsymbol{i}}$, such that $i$ : $1-3$, specifically (001), (010), and (100). At $700{ }^{\circ} \mathrm{C}$ and $0.7 \%$ strain, we observed some grains with slip bands following the $\{111\}$ planes (Fig. 10b) and other grains following the $\{100\}$ planes (Fig. 10e). However, at $700{ }^{\circ} \mathrm{C}$ and $1.0 \%$ stain, we see both octahedral and cubic slip planes being activated within the same grain (Fig. 10c,f). Higher applied strains results in increased resolved shear stresses on the slip systems, which were able to overcome the activation barrier for dislocation glide to accommodate the increased level of applied strain. A similar phenomenon is observed at $550{ }^{\circ} \mathrm{C}$, when strained to $1 \%$, the majority of the slip activity follows the $\{111\}$ planes, but some grains show slip bands following $\{100\}$ planes. Cubic slip plane activity was not observed at $550{ }^{\circ} \mathrm{C}$ and $0.7 \%$ strain. We can infer that at this intermediate temperature, if strain is increased, the activation energy for slip is surpassed on the cubic planes in certain grains.

These results have an important implication in the fatigue life of Ni-based superalloys. When submitted to high temperature and high strain $\left(700{ }^{\circ} \mathrm{C} \& 1 \%\right)$, both cubic and octahedral slip systems are activated in grains, allowing a well-distributed strain accommodation within favorably oriented grains and resulting in strain localization within distinct regions of the microstructure. If the temperature is reduced to intermediate values or macroscopic strain is reduced to a value below the nominal yield strain, the material will exhibit a more homogeneous strain distribution and less strain localization, leading to an increase in fatigue life. Fig. 11 shows a schematic summary of the slip plane activation previously discussed and shown in Figs. 9 and 10; therefore representing a deformation mechanism map for Ni-based superalloys.

The findings reported in this paper represent the first quantifiable study of cubic slip system activity at the mesoscale in polycrystalline $\gamma$ $\gamma$ ' Ni-based superalloys. Many studies have demonstrated the activation 

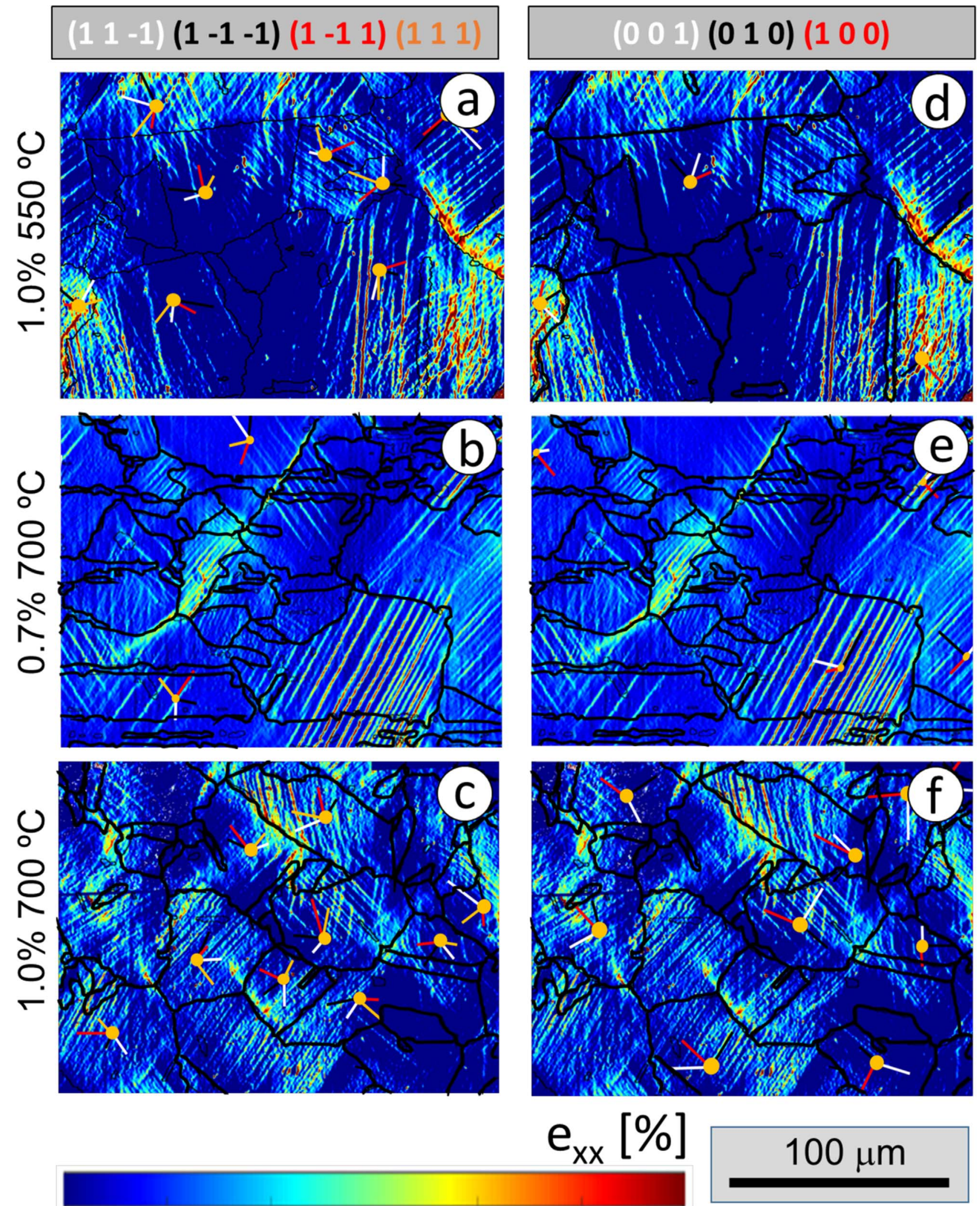

0

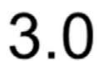

6.0

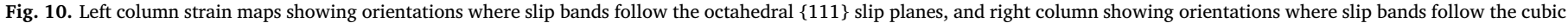
$\{100\}$ slip planes after 1 cycle. 


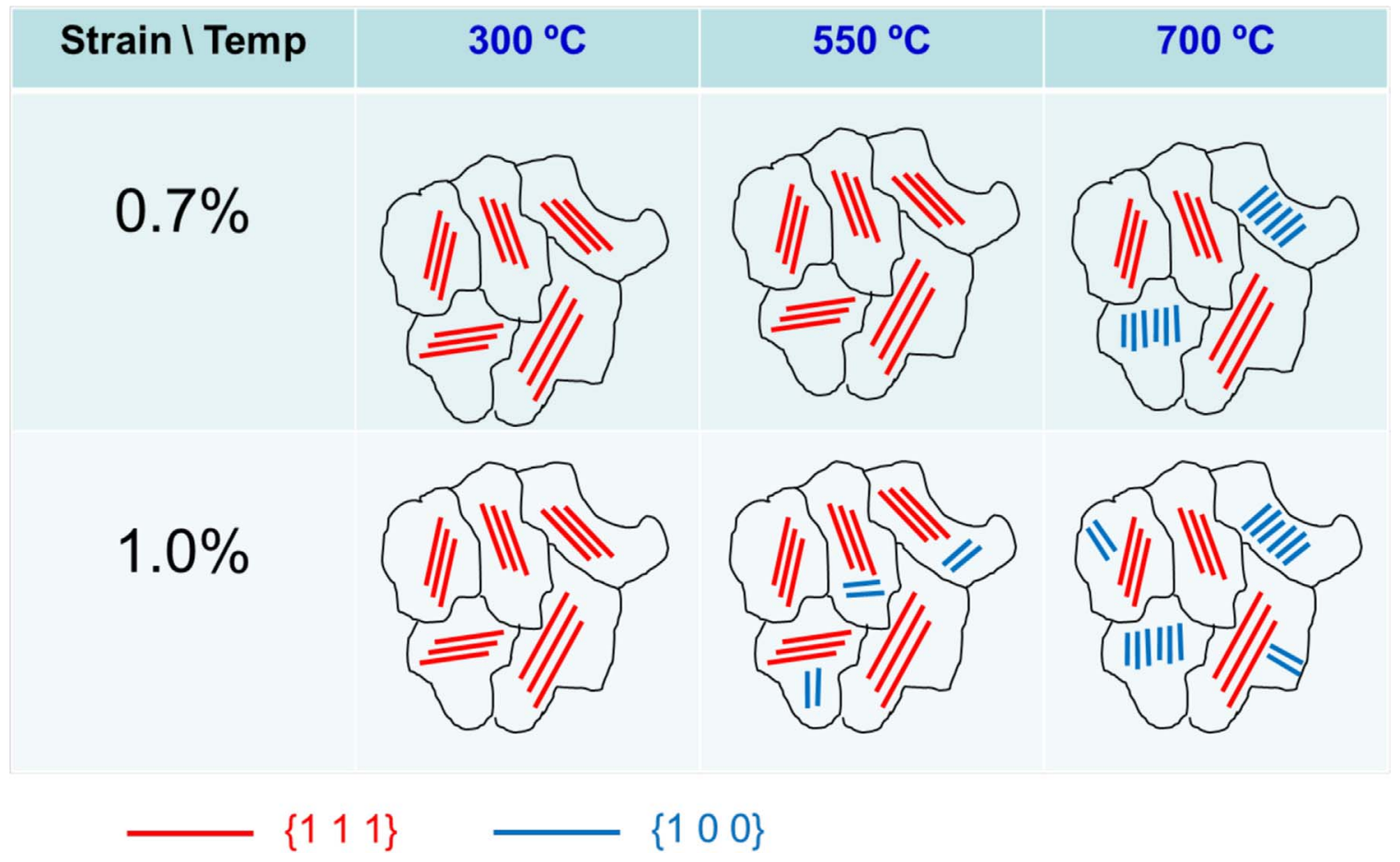

Fig. 11. Evolution of octahedral and cubic slip system activation as a function of temperature and macroscopic applied strain.

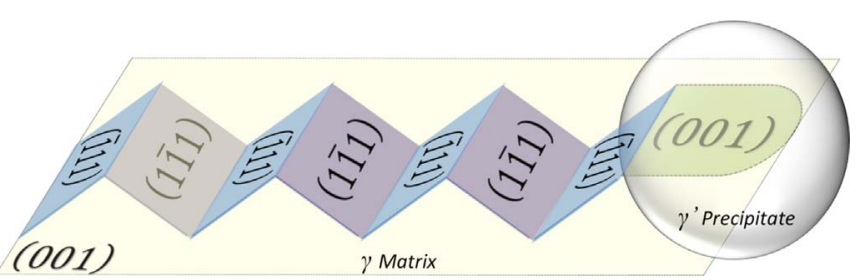

Fig. 12. Proposed mechanism for alternating zig-zagged slip along $\{111\}$ planes in the $\gamma$ matrix and shearing the $\gamma^{\prime}$ precipitate along a $\{001\}$ plane, at the mesoscale it appears that slip follows a $\{001\}$ plane, redrawn from $[18,44,45]$.

of cubic slip with increasing temperatures either via transmission electron microscopy (TEM) or atomistic simulations in ordered intermetalic $\gamma^{\prime}$ material. Yet the quantifiable results in this study represents a key advancement to calibrate the thermal activation components of polycrystalline deformation models and properly capture the kinetics of plasticity. It should be noted that TEM is needed to identify if the mesoscale cubic slip plane activity follows the zig-zag mechanism presented by Bettge and Österle [18] or if any signs of dislocation climb is present at elevated temperatures. As shown by Phillips et al. [44,45] via TEM investigation, dislocations cross-slip between $\{111\}$ planes in the $\gamma$ matrix and shear the $\gamma$ ' precipiates about the $\{100\}$ planes in a polycrystalline Ni-based superalloy, R104, under fatigue loading at $427^{\circ} \mathrm{C}$ and $704{ }^{\circ} \mathrm{C}$. It is inferred that given the similarities in the microstructure of both superalloys, the dislocation mechanisms in the present study follow a similar trend, as shown in Fig. 12. Thus, the $\gamma$ matrix has alternating slip along the $\{111\}$ planes, yet from a higher length scale, it appears slip follows the $\{100\}$ planes. Then the $\gamma$ ' precipitate is sheared about the $\{100\}$ planes. By conducting this experiment via SEM-DIC, we can thereby quantify the strain accommodated by both sets of slip planes, $\{111\}$ and $\{100\}$, at the mesoscale as a function of temperature.

\section{Conclusion}

This work has outlined considerable progress in quantifying polycrystalline deformation at the mesoscale within Ni-based superalloys.
High resolution DIC is used to conduct strain mapping relative to the microstructural features during interrupted fatigue experiments at various applied strain ranges and temperatures. Significant contributions of this study are summarized as follows:

1. The deformation in the strain maps is observed to be planar in characteristic and discrete slip bands are evident. Most of the slip bands are observed after the first cycle. While the quantity of strain accommodated within the slip bands increases during cyclic loading, new slip bands are not formed and the distances between slip bands are constant after the first loading cycle.

2. The strain maps elucidate the kinetics of plastic deformation at the grain scale, which include the thermally activated components of slip for an ensemble of dislocations. At increasing temperature, the strain accommodated within the bands increase and saturate at a lower number of applied loading cycles.

3. A deformation mechanism map is presented as a distinct shift in slip characteristic is observed with temperature and applied strain ranges. At lower temperatures $\left(300{ }^{\circ} \mathrm{C}\right)$, deformation is accommodated entirely by the octahedral slip planes $\{111\}$; while at elevated temperature $\left(700{ }^{\circ} \mathrm{C}\right)$, the cubic slip systems $\{100\}$ are also active. At the intermediate temperatures $\left(550^{\circ} \mathrm{C}\right)$, the introduction of higher applied strains activates deformation on the cubic slip planes.

\section{Acknowledgements}

The authors gratefully acknowledge funding from Rolls-Royce Corporation and the National Science Foundation (CMMI 13-34664). The authors would like to thank: Dr. Mark Hardy for insightful discussions and his encouragement; Iain Parr for providing the material and microstructure assessment; Dr. Jared Tracy and Professor Samantha Daly for insights into high temperature speckle patterns; Priya Ravi and Alexandra Mallory for assistance in data consolidation; John Rotella and Todd Book for helpful DIC discussions; and Jan Eberle for help in SEM repairs. All electron microscopy was performed in the Life Science Microscopy Facility, Purdue University. 


\section{References}

[1] G. Schoeck, A. Seeger, Defects in crystalline solids, Phys, Soc. Lond. (1955) 340 .

[2] U.F. Kocks, A. Argon, M.F. Ashby, Bonding patterns and Instabilites in the $\mathrm{m}=2$ Ruddlesden-Popper phases: LaSr2Mn2O7 and La2CaCu2O6, Prog. Mater. Sci. 19 (1975) 1-5, http://dx.doi.org/10.1016/0079-6425(75)90005-5.

[3] A. Argon, Strengthening Mechanisms in Crystal Plasticity, Oxford University Press on Demand, 2008.

[4] R.C. Reed, The Superalloys: Fundamentals and Applications, Cambridge University Press, 2008.

[5] D. Caillard, Yield-stress anomalies and high-temperature mechanical properties of intermetallics and disordered alloys, Mater. Sci. Eng. A 319 (2001) 74-83.

[6] B.J. Piearcey, B.H. Kear, R.W. Smashey, Correlation of structure with properties in a directionally solidified nickel-base superalloy, ASM Trans. Q. 60 (1967) 634-645.

[7] P. Beardmore, R.G. Davies, T.L. Johnston, On the temperature dependence of the flow stress of nickel-base alloys (Flow stress temperature dependence of $\mathrm{Ni}$-Cr-Al alloys consisting of gamma prime dispersion in $\mathrm{Ni}$ base solid solution), Metall. Soc. AIME Trans. 245 (1969) 1537-1545.

[8] B.H. Kear, H.G.F. Wilsdorf, Dislocation configurations in plastically deformed polycrystalline Cu3 Au alloys, Trans. Met. Soc. AIME 224 (1962) 382-386.

[9] A.E. Staton-Bevan, R.D. Rawlings, The deformation behaviour of single crystal Ni3(Al, Ti), Phys. Status Solidi 29 (1975) 613-622, http://dx.doi.org/10.1002/ pssa.2210290232.

[10] V. Paidar, D.P. Pope, V. Vitek, A theory of the anomalous yield behavior in L12 ordered alloys, Acta Metall. 32 (1984) 435-448, http://dx.doi.org/10.1016/0001 6160(84)90117-2.

[11] R.C. Reed, C.M.F. Rae, 22 - Physical Metallurgy of the Nickel-Based Superalloys A2 Laughlin, David E., in: K.B.T.-P.M. (Fifth E. Hono (Ed.), Elsevier, Oxford, 2014, pp. 2215-2290. http://dx.doi.org/10.1016/B978-0-444-53770-6.00022-8.

[12] D.M. Dimiduk, A.W. Thompson, J.C. Williams, The compositional dependence of antiphase-boundary energies and the mechanism of anomalous flow in Ni3 Al alloys, Philos. Mag. A 67 (1993) 675-698, http://dx.doi.org/10.1080/ 01418619308207184

[13] R.V. Miner, T.P. Gabb, J. Gayda, K.J. Hemker, Orientation and temperature dependence of some mechanical properties of the single-crystal nickel-base superalloy René N4: part III. Tension-compression anisotropy, Metall. Trans. A 17 (1986) 507-512, http://dx.doi.org/10.1007/BF02643957.

[14] G. Hoinard, R. Estevez, P. Franciosi, Hardening anisotropy of $\gamma / \gamma^{\prime}$ superalloy single crystals-I. Experimental estimates at $650{ }^{\circ} \mathrm{C}$ from a homogeneous analysis, Acta Metall. Mater. 43 (1995) 1593-1607, http://dx.doi.org/10.1016/0956-7151(94) 00352-I.

[15] M. Kolbe, K. Neuking, G. Eggeler, Dislocation reactions and microstructural instability during $1025^{\circ} \mathrm{C}$ shear creep testing of superalloy single crystals, Mater. Sci. Eng. A 234-236 (1997) 877-879, http://dx.doi.org/10.1016/s0921-5093(97) 00366-3.

[16] A. Nitz, E. Nembach, Anisotropy of the critical resolved shear stress of a $\gamma^{\prime}(47 \mathrm{vol}$ $\%$ )-hardened nickel-base superalloy and its constituent $\gamma$-and $\gamma^{\prime}$-single-phases, Mater. Sci. Eng. A 234 (1997) 684-686, http://dx.doi.org/10.1016/S0921 5093(97)00373-0.

[17] A. Vennemann, E. Langmaack, E. Nembach, On the temperature dependence of the critical resolved shear stress of the $\gamma^{\prime}$-strengthened superalloy NIMONIC PE16, Scr. Mater. 46 (2002) 723-728, http://dx.doi.org/10.1016/S1359-6462(02)00059-3.

[18] D. Bettge, W. [Federal I. for M.R. and T. (BAM) Oesterle Berlin (Germany)], "Cube slip" in near-[111] oriented specimens of a single-crystal nickel-base superalloy, 1999. http://dx.doi.org/10.1016/S1359-6462(98)00446-1.

[19] L. Méric, P. Poubanne, G. Cailletaud, Single crystal modeling for structural calculations: part 1-model presentation, J. Eng. Mater. Technol. 113 (1991) 162-170, http://dx.doi.org/10.1115/1.2903374.

[20] P.E. McHugh, R. Mohrmann, Modelling of creep in a Ni base superalloy using a single crystal plasticity model, Comput. Mater. Sci. 9 (1997) 134-140, http://dx doi.org/10.1016/S0927-0256(97)00067-0.

[21] S. Forest, F. Barbe, G. Cailletaud, Cosserat modelling of size effects in the mechanical behaviour of polycrystals and multi-phase materials, Int. J. Solids Struct. 37 (2000) 7105-7126, http://dx.doi.org/10.1016/S0020-7683(99)00330-3.

[22] T.T, W.A. M.B, M.G.D. Geers, Cube slip and non-Schmid effects in single crystal Nibase superalloys, Model. Simul. Mater. Sci. Eng. 18 (2010) 15005, 〈http://stacks. iop.org/0965-0393/18/i=1/a = 015005>.

[23] C.P. Przybyla, D.L. McDowell, Microstructure-sensitive extreme value probabilities for high cycle fatigue of Ni-base superalloy IN100, Int. J. Plast. 26 (2010) 372-394, http://dx.doi.org/10.1016/j.ijplas.2009.08.001.

[24] B. Lin, L.G. Zhao, J. Tong, H.-J. Christ, Crystal plasticity modeling of cyclic deformation for a polycrystalline nickel-based superalloy at high temperature, Mater. Sci. Eng. A 527 (2010) 3581-3587, http://dx.doi.org/10.1016/j.msea.2010. 02.045 .

[25] M.R. Daymond, M. Preuss, B. Clausen, Evidence of variation in slip mode in a polycrystalline nickel-base superalloy with change in temperature from neutron diffraction strain measurements, Acta Mater. 55 (2007) 3089-3102, http://dx.doi. org/10.1016/j.actamat.2007.01.013.

[26] M.A. Tschopp, B.B. Bartha, W.J. Porter, P.T. Murray, S.B. Fairchild, Microstructuredependent local strain behavior in polycrystals through in-situ scanning electron microscope tensile experiments, Metall. Mater. Trans. A 40 (2009) 2363-2368, http://dx.doi.org/10.1007/s11661-009-9938-6.

[27] A. Kammers, S. Daly, Experimental investigation of deformation mechanisms present in ultrafine-grained metals BT-MEMS and nanotechnology, in: T. Proulx (Ed.), Proceedings of the 2011 Annual Conference on Experimental and Applied Mechanics, 4 Springer New York, New York, NY, 2011, pp. 105-110, , http://dx. doi.org/10.1007/978-1-4614-0210-7_15.

[28] J.L.W. Carter, N. Zhou, J.M. Sosa, P.A. Shade, A.L. Pilchak, M.W. Kuper, Y. Wang, H.L. Fraser, M.D. Uchic, M.J. Mills, Characterization of strain accumulation at grain boundaries of nickel-based superalloys, Superalloys 2012 (2012) 43-52, http://dx. doi.org/10.1002/9781118516430.ch5.

[29] F. Di Gioacchino, J. Quinta da Fonseca, Plastic strain mapping with sub-micron resolution using digital image correlation, Exp. Mech. 53 (2013) 743-754, http:// dx.doi.org/10.1007/s11340-012-9685-2.

[30] J. Esquivel, M.D. Sangid, Digital image correlation of heterogeneous deformation in polycrystalline material with electron backscatter diffraction, Microsc. Microanal. 21 (2015) 1167-1168, http://dx.doi.org/10.1017/S1431927615006625.

[31] J.C. Stinville, N. Vanderesse, F. Bridier, P. Bocher, T.M. Pollock, High resolution mapping of strain localization near twin boundaries in a nickel-based superalloy, Acta Mater. 98 (2015) 29-42, http://dx.doi.org/10.1016/j.actamat.2015.07.016.

[32] M.P. Echlin, J.C. Stinville, V.M. Miller, W.C. Lenthe, T.M. Pollock, Incipient slip and long range plastic strain localization in microtextured Ti-6Al-4V titanium, Acta Mater. 114 (2016) 164-175, http://dx.doi.org/10.1016/j.actamat.2016.04.057.

[33] T.A. Book, M.D. Sangid, Strain localization in Ti-6Al-4V Widmanstätten microstructures produced by additive manufacturing, Mater. Charact 122 (2016) 104-112, http://dx.doi.org/10.1016/j.matchar.2016.10.018.

[34] B. Swaminathan, J. Lambros, H. Sehitoglu, Digital image correlation study of mechanical response of nickel superalloy Hastelloy X under thermal and mechanical cycling: uniaxial and biaxial stress states, J. Strain Anal. Eng. Des. 49 (2014) 233-243, 〈http://sdj.sagepub.com/content/49/4/233.abstract〉.

[35] R.B. Berke, J. Lambros, Ultraviolet digital image correlation (UV-DIC) for high temperature applications, Rev. Sci. Instrum. 85 (2014), http://dx.doi.org/10.1063/ 1.4871991.

[36] J.L.W. Carter, M.W. Kuper, M.D. Uchic, M.J. Mills, Characterization of localized deformation near grain boundaries of superalloy René-104 at elevated temperature, Mater. Sci. Eng. A 605 (2014) 127-136, http://dx.doi.org/10.1016/j.msea. 2014.03.048.

[37] J. Tracy, A. Waas, S. Daly, A new experimental approach for in situ damage assessment in fibrous ceramic matrix composites at high temperature, J. Am. Ceram. Soc. 98 (2015) 1898-1906, http://dx.doi.org/10.1111/jace.13538.

[38] I.M.D. Parr, T.J. Jackson, M.C. Hardy, D.J Child, C. Argyrakis, K. Severs, V. Saraf, J. M. Stumpf, Inhomogeneous grain coarsening behavior in supersolvus heat treated nickel-based superalloy RR1000, in: Proceedings of the 13th International Symposium of Superalloys, 2016, pp. 447-456 http://dx.doi.org/10.1002/ 9781119075646.ch48.

[39] M.A. Sutton, N. Li, D. Garcia, N. Cornille, J.J. Orteu, S.R. McNeill, H.W. Schreier, X. Li, A.P. Reynolds, Scanning electron microscopy for quantitative small and large deformation measurements part II: experimental validation for magnifications from 200 to 10,000, Exp. Mech. 47 (2007) 789-804, http://dx.doi.org/10.1007/s11340007-9041-0.

[40] M.A. Sutton, N. Li, D.C. Joy, A.P. Reynolds, X. Li, Scanning electron microscopy for quantitative small and large deformation measurements part I: SEM imaging at magnifications from 200 to 10,000, Exp. Mech. 47 (2007) 775-787, http://dx.doi. org/10.1007/s11340-007-9042-z.

[41] A.D. Kammers, S. Daly, Digital image correlation under scanning electron microscopy: methodology and validation, Exp. Mech. 53 (2013) 1743-1761.

[42] J.C. Stinville, M.P. Echlin, D. Texier, F. Bridier, P. Bocher, T.M. Pollock, Sub-grain scale digital image correlation by electron microscopy for polycrystalline material during elastic and plastic deformation, Exp. Mech. 56 (2016) 197-216, http://dx. doi.org/10.1007/s11340-015-0083-4.

[43] A.W. Mello, T.A. Book, A. Nicolas, S.E. Otto, C.J. Gilpin, M.D. Sangid, Distortion correction protocol for digital image correlation after scanning electron microscopy: emphasis on long duration and ex-situ experiments, Exp. Mech. (2016) EXME-D-16-00386.(Submitted for publication).

[44] P.J. Phillips, R.R. Unocic, L. Kovarik, D. Mourer, D. Wei, M.J. Mills, Low cycle fatigue of a Ni-based superalloy: non-planarnon-planar deformation, Scr. Mater. 62 (2010) 790-793.

[45] P.J. Phillips, R.R. Unocic, M.J. Mills, Low cycle fatigue of a polycrystalline Ni-based superalloy: deformation substructure analysis, Int. J. Fatigue 57 (2013) 50-57, http://dx.doi.org/10.1016/j.ijfatigue.2012.11.008. 